\title{
Bentham's Geometrics as Applied to the Internet Age and the Global Economy: Bentham 2.0
}

\author{
VINCENT-EMMANUEL MATHON
}

vemathon@gmail.com

The title of my paper could have been Bentham 2.0, as my purpose is to demonstrate that Bentham is the perfect philosopher of the internet age and his thoughts are very useful to understand our current globalised information society, most of all as far as economics are concerned. The raw material - the very phrase raw material is adequate indeed - that I have been using as a basis for this paper are the manuscripts of Bentham concerning mathematics as transcribed and analysed by Gianfranco Pellegrino in his excellent paper entitled 'The Benthams' Euclidean Training: Jeremy Bentham's Writings on Mathematics in their Historical and Theoretical Context'. ${ }^{2}$

We will start with the reasons why the pattern of Bentham's works is web compliant, we will then analyse his own vision of mathematics - and more specifically geometricsand, finally, we will analyse the utility of his vision of mathematics in our contemporary world and our internet-based economy.

Why is Bentham that web-compliant? I studied John Stuart Mill for my PhD thesis, and one of the main aspects of Mill's works is that he wrote in order to be published. Mill wrote well-arranged and organised books in accordance with the standards of Nineteenth Century publishers. Bentham aimed to have — and effectively had-his works published as well. But a large batch of his material is made up of various patches, scrambles, notes, more particularly as far as his manuscripts — which are the source that feeds this paperare concerned. Bentham would have enjoyed the computer age very much; he would have praised the 'copy and paste' function of word processors, and he would have loved the

\footnotetext{
${ }^{1}$ A version of this paper was delivered at the 'New Directions in Bentham Studies' conference, held at University College London on 9 December 2011.

${ }^{2}$ To be published in this volume of the Journal of Bentham Studies.
} 
hyperlink. Therefore, the structures of Bentham's works themselves are shaped for-or rather suit - the internet. The success of the award winning project Transcribe Bentham, ${ }^{3}$ promoted by the Bentham Project, is no coincidence. The phrase Bentham 2.0 does make sense indeed.

Along with the pattern of Bentham's works, the content - and more specifically mathematics - is likewise web-compliant and is useful for the internet age as well. One of the most interesting points in his mathematical works is the sharp criticism of Euclid. For instance, Bentham says:

The first and fundamental Axiom with all Euclid's Editors is that Euclid is infallible; the perpetual consequence is that if they find any thing they do not like, it is on that account done not on Euclid's but somebody else's. ${ }^{4}$

Such critics at the end of the Eighteenth Century were very rare indeed.

These critics have got two sides: the first side is composed of classical critics who date back from Democritus and Epicurus and from empiricism; the second side-which has not been apparently analysed or underscored in the literature yet-reveals how Bentham's approach can be considered as an alternative type of non-Euclidean tradition paving the way for mathematicians in the Nineteenth and the Twentieth Centuries.

The first side of the critique - the classical one-is that perfect figures as described in Euclidean geometry do not match reality in nature. For instance, concerning solids, Bentham says:

When Geometry speaks of bodies under the name of Solids it is not impenetrability it considers. Impenetrability does not enter into the combination is not one of the constituent Ideas fictitious entities of the word body it is étendue figure of 3 dimensions. ${ }^{5}$

This excerpt underscores the very concept of fictitious entities which are described in the

\footnotetext{
${ }^{3}$ Transcribe Bentham, http://www.ucl.ac.uk/transcribe-bentham, accessed 11 July 2012.

${ }^{4}$ UCL Bentham Papers (hereafter 'UC') cxxxv. 7.

${ }^{5}$ UC cxxxv. 56.
} 
following text:

Every point of view in which we can consider a real entity every way by which it can find a passage to our senses is said to be the effect of a fictitious entity. ${ }^{6}$

This use of the concept of fictitious entities resembles Epicurus's philosophy of perception. ${ }^{7}$ Vision of an item, according to Epicurus, is the result of small particlesreplicates - of the original item which are transferred onto the eye. To see actually means to experience the touchdown of the replicate on the eye. Bentham seems to support the same opinion with a subtle difference: the replicate does not necessarily land unaltered on the eye. It can be modified due to various actions and it depends on the point of view of the observer. For Bentham, Epicurus's replicates become fictitious entities, or fictions.

Physical reality is the ultimate criterion of truth though we perceive it through fictions. According to Bentham, mathematics can only be useful if they are connected to physical reality. Physical Reality is shaped by the quantity of matter. Geometrics must not refer to some abstract world but to matter as quantified by the quantity of matter.

By introducing this concept, Bentham opens up a new type of Non Euclidean Tradition. As a good example, let us analyse the following excerpt:

The facility of apprehensing the Quantity of Matter is as the Number of Parts into which it is broken; namely of such parts that the attention may stop and fix itself upon any One, without the Necessity of keeping hold of the next, at the same time. ${ }^{8}$

Bentham criticises the Euclidean geometry, as it implies a purely abstract approach not necessarily in touch with physical reality, not in touch with any material entities. The path that Bentham would instead prefer would consist of dividing figures up to a point where we finally obtain entities that are both connected to reality and independent from one another. This is what the phrase Quantity of Matter denotes. According to Bentham, geometry is not useful as long as it is not connected to material bodies. As material

\footnotetext{
${ }^{6} \mathrm{UC}$ cxxxv. 50.

${ }^{7}$ On Epicurus, see J. Salem, L'Atomisme antique (Démocrite, Epicure, Lucrèce), Paris, 1997, ch. II.

${ }^{8} \mathrm{UC}$ cxxxv. 11.
} 
bodies are not that easy to describe, matter itself must be quantified in this process, hence the phrase Quantity of Matter. Matter is quantified once we have found elements that cannot be divided, and that are at the same time-which means over a given period of time-independent from each other. All together, they quantify and thus shape material bodies. But each of them can evolve independently over this given period of time.

This is similar to the space phase concept as developed by the Nineteenth Century mathematician and physicist William Hamilton (1805-65) whose philosophy was examined — one would say criticized — by John Stuart Mill in his book An Examination of Sir William Hamilton's Philosophy [1865]. ${ }^{9}$ The concept of phase space stems from physicist Joseph-Louis Lagrange's (1736-1813) discoveries in the late Eighteenth Century; it is not a new scientific theory per se; it is a new way to express Newtonian physics. Instead of using traditional space and time references and a three dimension space, Hamilton chooses a model centered around the evolution of momentum, with time not being explicitly stated in the equations. This model evolves within a space of several dimensions, each dimension being the degree of liberty of a system. This is what we call a phase space. The degrees of liberty are independent from each other and all together, they can be used to draw the evolution of the system over a given period of time. They thus draw a virtual space, virtual yet connected to reality, evolving for a given period of time.

We therefore have the same pattern than Bentham, which means that we can assert that Bentham is at the outset of an alternative tradition of Non Euclidean mathematics, a tradition that will then be promoted by Hamilton- even though we cannot prove that Hamilton was directly influenced by Bentham — and to a certain extent, by mathematician Henri Poincaré (1854-1912) as well; that is the tradition of empirical Non-Euclidean mathematics. This comes as a difference from Georg Friedrich Bernhard Riemann's (1826-66) non-Euclidean geometries — which are far more notorious in the literature but which led to a logic separated from physical reality, to mathematics that were supposed to exist by themselves and for themselves. That was the dream of Friedrich Ludwig Gottlob Frege (1848-1925), Bertrand Russell (1872-1970), and was the

\footnotetext{
${ }^{9}$ J. S. Mill, ‘An Examination of Sir William Hamilton's Philosophy [1865], in The Collected Works of John Stuart Mill, ix, ed. J. M Robson and intro. A. Ryan, Toronto, 1979.
} 
overwhelming ambition of David Hilbert (1862-1943). But this project of consistent, self-sustained and detached from physical reality mathematics was ruined by Gödel remarkable theorem in 1931 which demonstrated that such mathematics would be necessarily incomplete and could not therefore be self-sustained. ${ }^{10}$

On the contrary, with Bentham, we can see a non-Euclidean tradition that is more practical, more useful, and that, as used in Hamilton's physics, corresponds to physical reality indeed.

In order to summarize the second side of the non-Euclidean approach, we can thus say that we have a set of independent elements, which, over a given period of time, draw a virtual space together; they all draw a common fiction-necessarily linked to physical reality as the elements represent the Quantity of Matter - a fiction that will unfold as a virtual space; this space is provisional, it has its own running time.

Bentham's views on geometries could thus be summarized this way:

1. Reality is processed through fictions and there is no reason to think that the Euclidean fiction is better than any other

2. Quantity of Matter is the item to be used as a connection between mathematics and physical reality

3. Quantity of Matter of one object, being all that can allow us to consider it independently from the rest, is the basis of the new mental spaces paving the way for an empirical non-Euclidean tradition.

Let us now analyse how this vision can apply to our internet society. The first question is what is physical reality in a society where both our lives and economy depend not only on material bodies, but equally on non-material entities, such as processed information? How could the concept of Quantity of Matter apply as our economy does not exclusively rest on matter? And hence, what should we do with the concept of Quantity of Matter? What if, for our information based society, we said Quantity of Information instead?

\footnotetext{
${ }^{10}$ See G. Potdevin, Logique et Mathématique, Paris,1990, ch. iv.
} 
And the gateway to information philosophy is Shannon's Theory of Information as stated in his 1948 article 'A Mathematical Theory of Communication'. In the introduction to this article, Shannon defines the purpose of information transmission:

The fundamental problem of communication is that of reproducing at one point either directly or approximately a message selected at another point. $^{11}$

Selecting a message means choosing a sequence of symbols from a set that contains a finite number of symbols. Such symbols can be letters, digits or anything else. Each symbol has its own duration, i.e. the minimum running time that it will take to transmit it. The transmission pattern consists of three items: the source of information, the channel and the receiver. Shannon's demonstration unfolds this way. He describes the concept of capacity as applied to the channel. He then studies the nature and property of a discrete source of information. Finally he describes the flow of information through the channel, both through a noiseless channel and through a channel with noise.

Shannon then analyses the way to quantify information, what is Quantity of Information indeed ${ }^{12}$

Can we define a quantity which will measure, in some sense, how much information is "produced" by such a process, or better, at what rate information is produced?

Shannon discovered that the adequate mathematical expressions to describe this probabilistic - or statistic - evolution of the source with time was similar to the way entropy as it had been shaped by Ludwig Boltzman (1844-1906) in statistical mechanics. Entropy is a peculiar concept. It was first created by Rudolf Clausius (1822-88) in order to explain the Second Principle of Thermodynamics and it was then formalized by Boltzman for statistical thermodynamics. Entropy is commonly-but unrightfullyconsidered as a synonymous for confusion; which is untrue. Entropy is a fiction which depicts — or translates into a scalar — both the irreversibility of time - it underscores the

\footnotetext{
${ }^{11}$ C. E. Shannon, 'A Mathematical Theory of Communication', The Bell Technical Journal, vol. 27 (1948), pp. 379-423, 623-656.

${ }^{12}$ Ibid., Part I Discrete Noiseless Systems 6. Choice, Uncertainty And Entropy
} 
fact that we cannot turn back Time - and the increasing complexity of phenomena over time. Entropy can thus be considered as a way to assess complexity. Shannon would rather compare it to the assessment of uncertainty, which is equivalent, as in his view, entropy quantifies the amount of information produced by the source.

Quantity of Matter, as transcribed into an information society becomes Quantity of Information and is therefore linked to entropy; it aims to quantify uncertainty and complexity. It means that physical reality-that of a world with material bodies \& information - must be assessed through the prism of structured unpredictability.

The first lesson that can be learnt from Bentham's geometrics as applied to the internet society is that corporate ventures, companies, individuals must learn to deal rationally and to keep cool within a randomized and randomizing society. The same result-i.e. the very necessity of randomizing smartly - can be obtained through the Theory of Chaos as described by Poincaré, and later developed by Ludvig Lorenz (182991), and his so-called butterfly effect. ${ }^{13}$

Quantity of Matter, as seen through the prism of information, is linked to randomizing. But if we get back to our interpretation of Bentham- or of the BenthamHamilton approach - Quantity of Matter shapes virtual spaces. Such spaces only last for a given period of time; they are not disconnected from reality but rely though upon fictitious entities.

Fictitious entities are a widespread feature on the internet, through Facebook profiles, or even web sites. A fiction being, in Bentham's terms, the altered replicate of the Real Entity ; all that is conveyed through the web can be described as a fiction as it, first, stems from some real entity, and, second, is de facto altered when digitized and poured into information networks. This necessarily implies a new perception of our world which has been, so far, Euclidean.

Geographical borders between nations are the results of our Euclidean perception of the world. Such geometrics will not apply to the internet where we can have much more

\footnotetext{
${ }^{13}$ On the Theory of Chaos, see the following: U. Bottazini, 'Poincaré, mathématicien et philosophe', Pour la science (French edition of The Scientific American), no. 4 (Aug/Nov 2000); D. Ruelle, Hasard et Chaos. Paris, 1991; J. Odiles and I. Prigogine, Les lois du chaos, Paris, 1994.
} 
in common in terms of file sharing, activities, chat, with an individual on the other side of the world than with our geographical neighbours. The type of geometrics that would best suit the description of a globalized internet-based society would be non-Euclidean, and, as we will see the Bentham-Hamilton tradition can be appropriate.

If we use this approach, we will first have to define our Quantity of Matter as related to our internet-based global economy and the various independent elements - that we may well call vectors if we use Hamilton's terminology - by which it can be described. As we said above, the phrase Quantity of Matter in a society, which is not based upon material bodies only, can become the Quantity of Information. The elements that we are looking for to draw our own virtual space, or phase space, are thus information vectors. Given a certain period of time, we will trace the information vectors that will evolve independently from each other. It is not therefore geographical vicinity that will select the vectors and draw the frame of our space; it is similarity in evolution over time. We then have a virtual space involving all the actors, and more specifically economic actors, all around the world, that have in common information vectors. Such actors thus create a virtual space over a certain period of time, they exchange, do business together, they produce wealth - as they are connected to reality - and disappear or re-appear on demand. They can form a cluster.

Such clusters stem from entities (companies, private investors, stock exchanges, businesses, consumers, vendors, purchasers) evolving similarly over a given period of time.

The framework, or the background of traditional commerce, was the geographical map of the world with businesses and companies working within, from and between frontiers based upon Euclidean geometry. The framework of commerce in a globalised, information-based society requires a new kind of mapping, a mapping based upon the Bentham-Hamilton type of non-Euclidean geometry. Business actors that have similar interests, or that will evolve similarly over a given period of time, will create a cluster, a virtual space that is not based upon the Euclidean drawing of land frontiers but upon lines of common interests and shared objectives.

The sphere of exchanges is not the world as we see it on a geographical map but a 
virtual — or fictitious — world based upon similarities of businesses over a given period of time. In such a situation, we are left with two major challenges: first to attach a precise mental image so that this sphere becomes obvious and self-evident for everybody, and second, to adapt our global tax system and economic rules that have been shaped so far from our Euclidean geographical vision of the world.

Bentham could thus be rightfully labelled Bentham 2.0 as the structure of his works is perfectly fitted for the internet age. Besides, his critics of Euclid raise him as one of the leading figures, along with Hamilton, of an alternative type of non-Euclidean geometrics. This new approach of geometry is adapted to model our current global economy. Such results were discovered in the manuscripts of Bentham. I am certain that if we keep exploring these manuscripts, we will unearth a quote or a remark that may be useful, not only for scholars but for economists and engineers as well. That is the reason why the Bentham Project and the Transcribe Bentham initiative must go on.

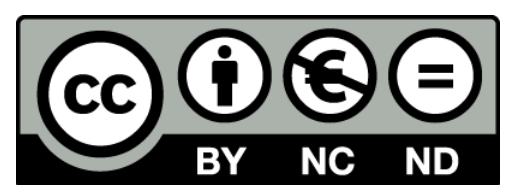

This work is licensed under the Creative Commons Attribution-NonCommercial-NoDerivs 2.0 UK: England \& Wales License. Under the terms of this licence, you are allowed to copy and distribute this work, but must give the original author credit. You not use this work for commercial purposes, nor alter or transform this work, without prior permission from the author. To view a full copy of this licence, visit: http://creativecommons.org/licenses/by-nc-nd/2.0/uk/ or send a letter to Creative Commons, 444 Castro Street, Suite 900, Mountain View. 